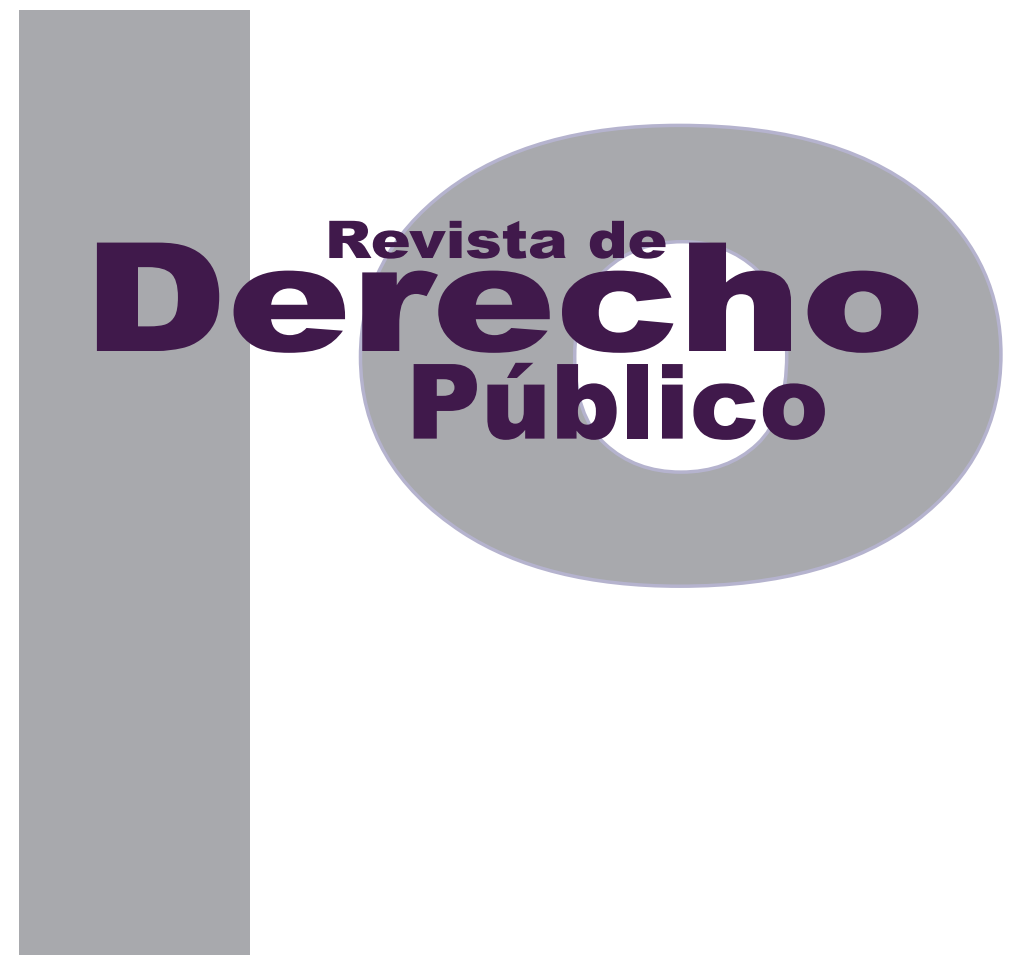

\title{
EL DERECHO HUMANO A TRABAJAR: LA CONCEPCIÓN DEL BANCO MUNDIAL Y LOS RIESGOS PARA EL CASO ARGENTINO
}

HORACIO JAVIER ETCHICHURY

Artículo de reflexión

Universidad de los Andes

Facultad de Derecho

Revista de Derecho Público N. ${ }^{\circ} 32$

Enero - Junio de 2014. ISSN 1909-7778 


\title{
El derecho humano a trabajar: la concepción del Banco Mundial y los riesgos para el caso argentino
}

\section{Resumen}

El presente artículo de reflexión tiene por objetivo describir el alcance dado por el Banco Mundial al derecho humano a trabajar, en su Informe Mundial de Desarrollo 2013, titulado Empleos. Primero se analiza, desde la hermenéutica jurídica, el contenido y las consecuencias posibles de las normas que garantizan el derecho humano al trabajo. También se revisan, para sostener la interpretación, las posturas doctrinarias y jurisprudenciales aplicables, junto a los pronunciamientos de los organismos competentes. Luego se contrasta dicha interpretación con la extensión reconocida en el informe del Banco Mundial y se ponen de manifiesto las insuficiencias y recortes que encierra el texto por él elaborado y sus propuestas de políticas públicas. Se hace especial referencia a los riesgos que entraña para Argentina la adopción de las nociones de este organismo especializado.

Palabras clave: Derecho a trabajar, derechos sociales, Banco Mundial.

\section{The human right to work: The World Bank's vision and the risks for Argentina}

\begin{abstract}
This article intends to describe the scope of the right to work in the World Bank's 2013 World Development Report: Jobs. In the first place, the article analyzes, from a legal prospective, the right to work as phrased in the main international human rights instruments. Academic comments and judicial developments are included in the analysis, as well as international organisms' contributions. Second, the article compares this interpretation to the World Bank's ideas on the issue, as expressed in the report. Through this comparison, the Bank's contradictions and restrictive constructions become apparent. Finally, the article describes the risks faced by Argentina as a borrower country if its policies are designed according to the World Bank proposals.
\end{abstract}

Keywords: Right to work, social rights, World Bank.

\section{O direito humano a trabalhar: a concepção do Banco Mundial e os riscos para o caso argentino}

\section{Resumo}

O presente artigo de reflexão tem como objetivo descrever o alcance dado pelo Banco Mundial ao direito humano a trabalhar, em seu Informe Mundial de Desenvolvimento 2013, titulado Empleos. Primeiro é analisado, desde a hermenêutica jurídica, o conteúdo e possíveis consequências das normas que garantem o direito humano ao trabalho. Também são revisadas, para sustentar a interpretação, as posturas doutrinárias e jurisprudenciais aplicáveis, junto aos pronunciamentos dos organismos competentes. Depois é contrastada dita interpretação com a extensão reconhecida no informe do Banco Mundial e é posta em manifesto as insuficiências e recortes que encerra o texto e suas propostas de políticas públicas. É feita uma referência especial aos riscos que entranha para a Argentina a adoção das noções deste organismo especializado.

Palavras-chave: Direito a trabalhar, direitos sociais, Banco Mundial. 


\section{SUMARIO}

Introducción - I. EL DERECHO HUMANO A TRABAJAR - A. El derecho humano a trabajar en la Constitución argentina - II. LA VISIÓN DEL BANCO MUNDIAL SOBRE LOS DERECHOS HUMANOS EN EL TRABAJO - A. El caso del trabajo infantil - III. CONCLUSIONES: LAS CONSECUENCIAS PARA ARGENTINA - Bibliografía. 


\title{
El derecho humano a trabajar: La concepción del Banco Mundial y los riesgos para el caso argentino ${ }^{1}$
}

\author{
Horacio Javier Etchichury²
}

Introducción

Este artículo de reflexión analiza la visión del Banco Mundial (Banco) acerca del derecho humano a trabajar y del alcance del resto de los derechos humanos en el ámbito laboral. Primero se revisa la forma en que se ha consagrado este derecho en el marco internacional y en Argentina. Luego se enumeran las contradicciones y limitaciones que el informe del Banco muestra en su lectura de los derechos humanos. Finalmente, se explican los riesgos que ello acarrea para un país como Argentina.

\footnotetext{
Cómo citar este artículo: Etchichury, H. J. (Junio, 2014). El derecho humano a trabajar: la concepción del Banco Mundial y los riesgos para el caso argentino. Revista de Derecho Público, 32.
}

2 Doctor en Derecho y Ciencias Sociales (Universidad Nacional de Córdoba, Argentina). Master of Laws (Yale Law School, Estados Unidos). Investigador Asistente, Consejo Nacional de Investigaciones Científicas y Técnicas (Conicet). Profesor Asistente, Facultad de Derecho y Ciencias Sociales, Universidad Nacional de Córdoba. Correo: etchichury74@gmail.com

\section{EL DERECHO HUMANO A TRABAJAR}

Suele afirmarse que la Constitución argentina consagra el derecho de trabajar, esto es, un derecho a que el Estado o los particulares no interfieran con el desarrollo de una tarea remunerada. Es una libertad negativa, propia de una concepción liberal. Su objetivo sería eliminar cualquier restricción impuesta en el ingreso o permanencia en el mercado del trabajo; es el paso del mundo laboral medieval al capitalista. De ninguna manera, se afirma, es un derecho a que cada persona reciba un puesto de trabajo (Sagüés, 2007, p. 808). Una idea similar sostuvo la Corte Suprema argentina en "Aranda" (1992), un fallo anterior a la reforma constitucional de 1994.

Precisamente, esta reforma modificó el panorama al dotar de jerarquía constitucional a un conjunto de tratados internacionales de derechos humanos. Estos instrumentos garantizan algo muy distinto. El art. 6 del Pacto de Derechos 
Económicos, Sociales y Culturales (PDESC) consagra explícitamente el derecho a trabajar, ${ }^{3}$ que "comprende el derecho de toda persona a tener la oportunidad de ganarse la vida mediante un trabajo libremente escogido o aceptado". No es el derecho a conservar un empleo específico (Harvey, 2002, pp. 371-373, 381).

El PDESC establece que los Estados "tomarán medidas adecuadas para garantizar ese derecho", y entre ellas incluye "programas, normas y técnicas encaminadas a conseguir (...) la ocupación plena y productiva". De modo que el Estado no puede solo confiar en la evolución propia de la economía como fuente de nuevos puestos. Existe un deber estatal de actuar, con mayor o menor vigor, para alcanzar el pleno empleo, situación en la que toda persona tenga un trabajo que pague un salario adecuado. En cambio, muchos economistas sostienen, en contra de este derecho, que debe haber un nivel de desempleo suficiente para evitar presiones inflacionarias (Harvey, 2002, pp. 405, 468).

El pleno empleo se encuentra dentro de los objetivos de las Naciones Unidas (NU), la organización impulsora del PDESc, según se especifica en los arts. 55 y 56 de su Carta (un tratado internacional vinculante para los Estados).

El contenido del derecho ha sido desarrollado por el Comité de Derechos Económicos, Sociales y Culturales (Comité) de nu. En su Observa-

3 El art. 23 de la Declaración Universal de Derechos Humanos de 1948 consagra el derecho al trabajo (art. 23). También la Declaración Francesa de los Derechos del Hombre y del Ciudadano, de 1793, establece (art. 21) el deber de la sociedad de procurar un empleo a cada persona, o los medios de subsistencia a quien no pueda trabajar. ción General $18^{4}$ (og 18), el Comité ratifica que se trata de un derecho individual; y si bien aclara que no debe entenderse como "un derecho absoluto e incondicional a obtener un empleo", sí impone numerosas obligaciones a los Estados. En particular, la de tomar todas las medidas necesarias para el desarrollo progresivo de este derecho y alcanzar el pleno empleo. La progresividad, agrega el Comité, significa también no adoptar medidas regresivas, esto es, que recorten o restrinjan la vigencia del derecho, por ejemplo, reduciendo el número de empleos existentes. A la vez, la og 18 explica que se debe tener en cuenta este derecho al negociar créditos con instituciones internacionales, como el Banco o el Fondo Monetario Internacional (FMI). Numerosas investigaciones señalan que los ajustes estructurales, receta frecuente de estas instituciones, afectan la vigencia de los derechos del trabajador. Por ejemplo, las privatizaciones implican despidos y el fin de subsidios en muchos servicios; la liberalización del comercio exterior afecta a las empresas locales y la flexibilización laboral deteriora los derechos del trabajador; el alza de la tasa de interés favorece el desempleo (Abouharb y Cingranelli, 2007, pp. 11-12). En la og 18, el Comité destaca que este artículo debe leerse en conjunto con los que definen las condiciones de un trabajo digno (arts. 7 y 8). Esto supone un ingreso que como mínimo cubra "condiciones dignas de existencia", según las define el PDESc mismo, incluyendo los diversos derechos consagrados (alimentación, salud, educación, vestido, vivienda, etcétera), tanto para la persona que trabaja como para su

4 Aprobada en el trigésimo quinto periodo de sesiones, año 2005. 
familia. A la vez, se debe garantizar igual paga por igual tarea, sin discriminaciones, y todas las libertades sindicales. Las vacaciones y otros períodos de descanso pago integran también la noción de trabajo digno.

En síntesis, se trata de un derecho conectado con la noción de dignidad y con un conjunto de otros derechos sociales, tales como la huelga, la sindicalización, el descanso y la formación, además de una remuneración que permita sostener la vida digna de quien trabaja y su familia. A la vez, promueve el cumplimiento de todos los demás derechos sociales, ya que el trabajo incrementa los recursos y la riqueza de la comunidad (Harvey, 2007, p. 118; 2002, pp. 466-467).

En cuanto a las medidas, en general se toma como la posibilidad más progresista la llamada estrategia keynesiana, seguida, por ejemplo, en los Estados Unidos, durante la década de 1940. Consiste en estimular al sector privado para que allí surjan los puestos de trabajo. Sin embargo, hay quienes sostienen que no puede excluirse la creación directa de empleos por parte del Estado. Esta modalidad se propuso en los comienzos del New Deal. El informe elevado en 1935 al presidente Roosevelt, por el Comité de Seguridad Económica, sugiere que el Gobierno debe lograr el "empleo asegurado -a través de la estimulación del empleo privado y la provisión de trabajos públicos para los trabajadores capaces que no puedan ser contratados por la industria en un período determinado"; este empleo público debe estar adecuadamente planificado (Committee on Economic Security, 1935). Esta medida toma en cuenta el problema de la falta de puestos, y no solo las barreras estructurales (discriminación, por ejemplo). Además, provee un mecanismo que puede reclamarse judicialmente en caso de que los Estados incumplan este derecho (Harvey, 2007, pp. 122, 139).

\section{A. El derecho humano a trabajar en la Constitución argentina}

En nuestro país, este derecho tiene rango constitucional. Ya anticipamos que la reforma de 1994 dio jerarquía constitucional a varios tratados de derechos humanos, a través del art. 75 inc. 22 de la Constitución Nacional (CN). El PDESC está incluido en ese conjunto, y su texto se debe leer en sintonía con el resto de los derechos de las personas que trabajan, incluyendo los contenidos en el art. 14 bis. Una cuestión de derechos humanos, en Argentina, es también una cuestión constitucional.

Esto significa que ninguna norma, ni actividad u omisión estatal o de particulares puede contradecir este derecho al trabajo. Si se produce una violación, las personas afectadas pueden reclamar judicialmente su protección a través de un amparo (previsto en el art. 43 de la cN). El control de constitucionalidad argentino está en manos de todos los jueces y sus efectos rigen solo para el caso concreto. Es, pues, un control judicial difuso, similar al vigente en Estados Unidos. Sin embargo, la Ley Suprema argentina admite la posibilidad de amparos interpuestos por ciertas entidades no gubernamentales o por el Defensor del Pueblo a nombre de sectores o grupos. Por lo tanto, una sentencia que declare 
la inconstitucionalidad de una política laboral puede tener efectos amplios. Incluso, si el Estado no adopta políticas concretas para asegurar el derecho a trabajar puede configurarse una inconstitucionalidad por omisión (Sagüés, 2007, pp. I, 111-113; Bidart Campos, 1991, pp. 351, 414; Quiroga Lavié, 2000, pp. 237-238). En ese supuesto, se viola la Constitución al no realizar un acto obligatorio: reglamentar.

El derecho a trabajar genera, como la mayoría de los derechos, obligaciones negativas y positivas, esto es, obligaciones de no hacer y de hacer. No se trata de un derecho solo positivo o negativo: en general, los derechos implican un conjunto de obligaciones en ambos sentidos, un continuum (Sepúlveda, 2006, p. 122; Abramovich y Courtis, 2002, p. 25). Por lo común, la Corte Suprema ha aplicado este derecho solo en su faz negativa, esto es, como protección contra el despido arbitrario o discriminatorio, incluyendo el practicado por empresas privadas. Para citar un ejemplo representativo de esa tendencia: en “Álvarez" (2010), la mayoría de la Corte ordenó la reinstalación de trabajadores despedidos en virtud de su actividad sindical. Entre los fundamentos, cita el derecho a trabajar, analizado en la OG 18 del Comité, al que la Corte reconoce como "intérprete autorizado del Pacto en el plano universal" (voto de la mayoría, cons. 7).

Pero no se ha desarrollado en casos judiciales el aspecto positivo de este derecho, es decir, aquel que obliga al Estado a realizar ciertas acciones, y no solo a abstenerse de conductas prohibidas. Tampoco se ha discutido en el máximo tribunal el vínculo de este derecho con la obligación estatal de alcanzar el pleno empleo. La Corte sí ha puesto en vigor, en cambio, las aristas positivas de otros derechos. En "Asociación Benghalensis" (2000), obligó al Estado a proveer tratamiento gratuito completo a las personas portadoras de VIH. Como medida cautelar en el caso "Rodríguez" (2006), ordenó a las autoridades suministrar alimentación y tratamiento médico a niños de una familia afectada por la pobreza. Recientemente, el fallo “Q. C.” (2012) señaló que en ciertas circunstancias extremas, los jueces pueden ordenar al Estado la provisión de una vivienda para quien la reclama a través de un amparo. Aún no se conoce si la lógica de estas sentencias sería seguida al analizar un reclamo judicial basado en el aspecto positivo del derecho humano al trabajo.

\section{LA VISIÓN DEL BANCO MUNDIAL SOBRE LOS DERECHOS HUMANOS EN EL TRABAJO}

El Ilamado Grupo Banco Mundial abarca un conjunto de instituciones, entre las que se destaca el Banco Internacional de Reconstrucción y Fomento (BIRF), que toma recursos del mercado internacional de capitales. En este trabajo denominamos Banco al BIRF. ${ }^{5}$ En 2007, el Banco

5 Tanto el Banco como el FMı fueron fundados en 1944 durante la Conferencia celebrada en Bretton Woods (Estados Unidos). El Banco no se gobierna de acuerdo con el principio de voto igualitario. Al contrario: las decisiones se toman por voto ponderado, donde cada Estado vota según los fondos que aporta. Estados Unidos tiene el 16,8\% de las acciones en el Banco y los países del G8, el 44\% (Abouharb y Cingranelli, 2007, p. 108). La máxima autoridad formal es la Junta de Gobernadores, integrada por un representante de cada país socio, que sesiona una vez al año. La mayoría de las atribuciones se delega a la Junta de Directores Ejecutivos, que se reúne dos veces a la semana y toma todas las decisiones importantes, incluyendo la aprobación o rechazo de los créditos propuestos. Cada uno de los cinco socios principales 
contaba con aproximadamente 12.500 personas de 160 países diferentes; el 40\% de ellas estaba trabajando en oficinas situadas en los distintos países prestatarios (Banco Mundial, 2007, pp. 13, 60, 87; Sarfaty, 2009, p. 647).

Es posible comprobar la influencia del Banco a través del monto de recursos que maneja. Presta entre 20 y 25 mil millones de dólares al año, mientras que, por ejemplo, el Programa de Naciones Unidas para el Desarrollo (PNUD) gasta menos de 3 mil millones anuales. Los países que reciben préstamos tienen un ingreso medio y, en general, también pueden financiarse con la banca privada (Killinger, 2003, p. 74; Banco Mundial, 2007, p. 76).

El Banco surge para promover la reconstrucción europea de posguerra. Hasta 1956, casi 2/3 de sus préstamos se otorgan a países de Europa. Luego, continúa su misión con los países en desarrollo. En América Latina impulsa la industrialización y las obras de infraestructura. Cuando Robert McNamara asume la presidencia de este, en 1968, el tema central de la institución pasa a ser la pobreza: se financian proyectos agrícolas y educativos, por su probable impacto positivo sobre dicha condición (Corbalán, 2002, pp. 67-68). Muchas de estas iniciativas no tienen éxito, en parte debido al conflicto con los intereses políticos de los mayores accionistas del Banco, esto es, los países centrales (Kanbur y Vines, 2000, pp. 101-103).

(Estados Unidos, Gran Bretaña, Japón, Alemania y Francia) designa un director ejecutivo. El resto de los países forma agrupamientos, sumando su poder de voto, para poder nominar a un director que represente a ese conjunto (Ghazi, 2005, p. 21; Banco Mundial, 2007, p. 8). Esto explica la mayor incidencia de los países centrales.
Hasta 1980, el Banco otorgó créditos para proyectos específicos (diques, plantas de energía); luego, se dedicó a programas de ajuste estructural, de alcance mucho más amplio, que impulsan el comercio y la inversión orientada a exportar, de acuerdo con las líneas del Ilamado Consenso de Washington. Este conjunto de principios neoliberales tiene el objetivo de transferir el poder desde el Estado hacia el mercado (Abouharb y Cingranelli, 2007, p. 3). Las pautas incluyen la disciplina fiscal estricta, las privatizaciones, la desregulación en el comercio y el sector financiero y los recortes en el gasto social (Ghazi, 2005, p. 46). Estos créditos basados en políticas (policy-based lending) llevan al Banco otra vez a los primeros planos en el gerenciamiento de fondos destinados a los países en desarrollo. A partir de 1999, los préstamos de ajuste estructural se convierten en los más frecuentes, superando a los que se aplican a proyectos concretos u obras de reconstrucción, que deberían ser la regla, según las normas fundantes del Banco. Más de 400 de estos créditos se aprueban entre 1981 y 2003 (Abouharb y Cingranelli, 2007 , pp. $25,58,63$ ). Se afirma que la pobreza disminuirá a partir del crecimiento basado en el ajuste estructural. En su informe anual de 1990, el Banco propone dos líneas centrales para la lucha contra la pobreza: por una parte, promover actividades que necesiten mano de obra intensiva; por la otra, crear redes de protección social para atenuar los efectos del ajuste (Kanbur y Vines, 2000, p. 101). Muy a menudo, los vaticinios optimistas del Banco fracasan. Los países que ajustan no crecen, o lo hacen a un ritmo demasiado lento, mientras disminu- 
yen o hacen desaparecer los fondos destinados a infraestructura pública, salud y educación. En tanto, sigue creciendo la deuda externa de cada una de estas naciones (Abouharb y Cingranelli, 2007, pp. 3, 9). En 1990, una publicación técnica del Banco admite que tras nueve años de políticas de ajuste, "pocos resultados claros se han obtenido en cuanto al éxito de estos programas" (Ribe, Carvalho, Liebenthal, Nicholas y Zuckerman, 1990). Pese a todo, continúa promoviéndose el crecimiento mediante versiones renovadas del ajuste estructural, que se basa en la noción de reducir el Estado ampliando el mercado. En los últimos años, el Banco enumera entre sus tareas financiar las necesidades de largo plazo para el desarrollo humano y social, apoyar a los países en crisis económica, promover reformas políticas e institucionales y crear un clima favorable para las inversiones (Banco Mundial, 2007, pp. 12-13). La pobreza no se define como una cuestión de derechos humanos, sino como un problema técnico-económico con proyecciones políticas. El Banco se dedica a proponer soluciones técnicas, pero sin considerar los derechos humanos (y en particular, los derechos sociales) como un límite a las opciones disponibles (Darrow, 2003, pp. 19, 51, 149).

Alegando su carácter técnico y su obligación de no interferir en la política interna de los países clientes, el Banco no admite expresamente estar obligado por los instrumentos internacionales de derechos humanos (Ghazi, 2005, pp. 82-83). Este carácter no-político le permite preservar su imagen de entidad técnica, la cual le resulta útil para recaudar fondos en los mercados internacionales de capital (Killinger, 2003, p. 3). Aunque formalmente es un ente especializado de Naciones Unidas bajo la supervisión del Consejo Económico y Social, no se subordina a los pactos creados en el ámbito de esa organización internacional. La falta de un consenso entre los especialistas acerca de este punto favorece su posición (Sarfaty, 2009, pp. 658-659; Banco Mundial, 2007, p. 40).

Otras instituciones similares, como la Unesco, siguen un enfoque explícito de derechos humanos. Sin embargo, el Banco no posee ninguna política operativa en la materia. En los últimos años incluye referencias indirectas y parciales a los derechos humanos y lleva a cabo actividades relacionadas con ellos. No obstante, su línea argumental más sostenida es que se dedica a crear el desarrollo indispensable para la vigencia de los derechos sociales, entre otros derechos humanos (Ghazi, 2005, p. 60). Así lo ha expresado, por ejemplo, en su comunicación ante la Conferencia de Naciones Unidas sobre Derechos Humanos, en 1993 (Banco Mundial, 1993, párr. 13 y 14). No parecen confirmarse en la realidad tales ideas. Un estudio empírico demuestra que los programas de ajuste estructural del Banco y el fmı debilitan el respeto por los derechos humanos, afectando particularmente los derechos económicos y sociales, en especial los de las personas más pobres (Abouharb y Cingranelli, 2007, pp. 230, 234-235; Darrow, 2003, p. 69).

Hoy el Banco es considerado también una institución educadora por sus amplios esfuerzos de investigación y difusión, si bien se le critica la insuficiente atención al trabajo de otras entida- 
des dedicadas al desarrollo. Probablemente no tiene conocimiento adecuado sobre ideas alternativas; la mayoría de su personal técnico, más allá de su nacionalidad de origen, se ha formado en un mismo entorno: las escuelas de posgrado de Estados Unidos. A través de sus informes e investigaciones el Banco propone a los países prestatarios nuevas razones para solicitar préstamos y plantea temas y preocupaciones que sirven de base para nuevos proyectos (Fine, 2002, pp. 205-207; Sindzingre, 2004, pp. 166, 168, 174). En sus intervenciones conceptuales intenta resignificar la historia y las relaciones políticas de los países prestatarios, además de constituirse en "financiador y artífice de las políticas nacionales de los países pobres" (MuriIlo, 2008, pp. 103-104). Incluso ha dado cada vez más peso a la noción de buen gobierno o gobernanza (good governance) como condición para el desarrollo, en una posición claramente política que desmiente su aparente apoliticidad (Klein, 1999, p. 105). Entre sus muchas publicaciones, el World Development Report tiene un lugar prominente. Este informe anual expone sus preocupaciones e ideas actuales $y$, si bien no es el elemento definitorio de las políticas propuestas, expresa la evolución de su pensamiento, sus posturas sobre cierto tema (Sindzingre, 2004, p. 166; Killinger, 2003, p. 66).

La edición 2013 está dedicada a la cuestión del empleo (Banco Mundial, 2012). Su objetivo es definir qué trabajos son positivos desde el punto de vista del desarrollo, y revisar qué políticas Ios fomentan. El texto enfatiza que "el desarroIlo se produce a través del empleo", ya que el trabajo "es la vía más efectiva para salir de la pobreza". A continuación, exponemos cómo el Banco intenta introducir el lenguaje de los derechos humanos en esta publicación, a la vez que mantiene la lectura más estrecha posible sobre estos derechos.

El informe 2013 ha sido saludado, en general, con comentarios positivos. Se ha elogiado su exhaustiva revisión de la bibliografía existente, lo cual ha sido definido oficialmente por la Organización Internacional del Trabajo (отт) como un "logro mayor", mientras destaca que tiene "mucho en común con el informe" y agradece el estrecho intercambio entre sus técnicos y el equipo del Banco que lo redactó (oIt, 2012). Se resalta también que el texto ofrece una perspectiva más equilibrada: por ejemplo, presenta o discute políticas heterodoxas, o al menos no incluidas en el Consenso de Washington. En algunos casos, el informe se abstiene de indicar una solución para los problemas descriptos, o advierte que no hay un remedio infalible para ellos. Por ejemplo, admite que los déficits presupuestarios "son más o menos preocupantes según la velocidad a que esté creciendo la economía"; también afirma que "la independencia de los bancos centrales debe evaluarse a la luz de la coherencia con el resto de la estrategia de desarrollo de cada país". Ambas aseveraciones parecen compatibles con una actitud más abierta hacia el pensamiento económico heterodoxo. En un comentario sobre la crisis de 2008 reconoce que se han reabierto "agitados debates en torno al nivel adecuado de regulación sobre el sector financiero" (Banco Mundial, 2012, pp. 23, 294). Por pasajes como estos, la oІт (2012) elogia el informe señalando que se aparta de 
las "soluciones únicas" y que no promueve la tradicional receta de flexibilización laboral. De hecho, el texto del Banco reconoce que "no hay consenso en cuanto al contenido de las políticas laborales", debido a la "polarización" de las posturas (Banco Mundial, 2012, pp. 26, 260).

Una de las innovaciones más importantes del informe es que menciona explícitamente a los derechos humanos. Sin embargo, como exponemos a continuación, estas referencias pierden todo su potencial a medida que se restringe el concepto a lo largo de las sucesivas páginas: hay por lo menos tres definiciones de lo que se entiende por derechos humanos aplicables en materia de empleo, cada una más reducida que la anterior.

Definición 1. En las páginas iniciales, el informe propone una interesante y amplia definición de empleo: "las actividades que generan un ingreso, monetario o en especie, sin violar los derechos humanos" (Banco Mundial, 2012, p. 5). En el mismo párrafo sostiene que las normas internacionales fijan los derechos humanos básicos como "las fronteras de lo que es inaceptable" [énfasis agregado]; entre esas normas menciona explícitamente la Declaración Universal de Derechos Humanos (DUDH) de 1948 y la Declaración de Principios y Derechos Fundamentales en el Trabajo, de 1998, impulsada por la оाт, ${ }^{6}$ que contiene cuatro pautas básicas: “a) la libertad de asociación y la libertad sindical y el reconocimiento efectivo del derecho de negociación

6 Disponible en http://www.ilo.org/public/spanish/standards/relm/ilc/ilc86/ com-dtxt.htm colectiva; b) la eliminación de todas las formas de trabajo forzoso u obligatorio; c) la abolición efectiva del trabajo infantil; y d) la eliminación de la discriminación en materia de empleo y ocupación" (art. 2).

Esta definición basada en los derechos humanos implica varias consecuencias de interés. Por ejemplo, no puede hablarse de empleo si el salario pagado no es justo, o si las condiciones de trabajo no son seguras y saludables, o cuando no hay descanso periódico pago, ya que todas estas condiciones están incluidas en el art. 23 de la DUDH. Si los derechos humanos trazan, según afirma el Banco, el límite de lo aceptable, ¿qué cabe decir acerca de las políticas de flexibilización y despidos masivos, usualmente impulsadas por este y otras entidades internacionales?, ¿no son acaso violatorias de los derechos humanos?, ¿son, por lo tanto, “inaceptables" (según el término por él mismo utilizado)?

Definición 2. En las secciones siguientes, el informe va recortando el alcance de los derechos humanos en juego. Así, afirma que no son empleos "las actividades (...) que involucran violaciones de derechos humanos fundamentales" (Banco Mundial, 2012, p. 49; énfasis añadido). No está claro cuál es el alcance de ese concepto, pero ya incluye una delimitación. Quizá algunos de los derechos incluidos en la DUDH, como las vacaciones pagas, no alcancen a ser fundamentales y, en tal caso, un trabajo sin descanso pago podría, de todas formas, ser considerado un empleo "aceptable" (otra vez, de acuerdo con la palabra usada por el Banco). En un tramo posterior, el límite se fija en los “derechos huma- 
nos básicos" (p. 65, énfasis agregado), y aunque se cita de nuevo la DuDH, esta vez solo se mencionan el derecho al trabajo y a la no discriminación contenidos en ella. Ahora las condiciones seguras y saludables y los salarios justos, por ejemplo, han quedado en el camino.

Definición 3. Así, el Banco puede efectuar una reformulación profunda. En el final del capítulo 1 , el informe ofrece una nueva definición de empleo: "las actividades que generan un ingreso real, monetario o en especie, y que no violan los principios y derechos fundamentales en el trabajo" (Banco Mundial, 2012, p. 66), en una clara referencia a la Declaración de la oाt de 1998, a través de la mención de su título. En solo sesenta páginas el texto pasa de una definición amplia de los derechos humanos como la base normativa para reconocer los empleos "aceptables" a una estrecha enumeración de los cuatro principios fundamentales de la oIT.

Es un cambio destacable: en unos pocos pasos, el Banco mueve la frontera entre lo "aceptable" y lo "inaceptable" (para usar sus propios términos). Veamos cómo lo hace. Reduce el espectro de derechos humanos aplicables a la relación laboral y eso, a su turno, amplía el número de trabajos "aceptables". Tomemos un ejemplo concreto. Supongamos que una persona es contratada para un empleo donde no está previsto el disfrute de un período anual de descanso pago. Esto viola el art. 24 de la DuDH, que garantiza el derecho a las "vacaciones periódicas pagadas". Ahora nos preguntamos: ¿se trata de un empleo "aceptable" o "inaceptable”, según los términos usados por el Banco? La respues- ta varía. Si tomamos la definición 1, el empleo es "inaceptable" porque no respeta la DUDH. En cambio, bajo la definición 2 no está claro si es "aceptable", por lo menos hasta que dilucidemos si las vacaciones pagas son un derecho fundamental o bien básico. Por último, si adoptamos la definición 3, el empleo es claramente “aceptable", porque negar vacaciones periódicas pagadas no viola ninguna de las cuatro pautas básicas de la oır.

Como muestra este ejemplo, hay empleos que pueden pasar del ámbito de lo "inaceptable" al terreno de lo "aceptable" a medida que el Banco va restringiendo su concepción de derechos humanos. Bajo la definición 1, las exigencias a la patronal son altas, abarcan varias pautas y regulan diferentes aspectos de la relación laboral. Al llegar a la definición 3, se requiere mucho menos por parte del empleador y ello vuelve "aceptables" (según el Banco) muchas modalidades de trabajo que no respetan la DuDH. En el caso argentino, como ya vimos, cada contradicción con la DUDH (o el PDESc, por ejemplo) implica la violación de un derecho constitucional.

Todo el resto del informe se centra en la Declaración de la oıт, que según el Banco es una regla clara, el "programa global de los derechos laborales", el núcleo central que "provee una base" y "ofrece una guía para reconocer lo inaceptable" en las cuatro áreas cubiertas por la Declaración: trabajo infantil, discriminación, trabajo forzado y libertad de asociación y negociación colectiva (Banco Mundial, 2012, pp. 25, $155,156,297)$. Como vemos, el nuevo piso en materia de derechos humanos ya no es la DUDH, 
sino la Declaración de la oІт. Alston y Heenan (2004) afirman que este abordaje -nacido en el ámbito del comercio internacional, y no en los movimientos sindicales- encubre el objetivo de reemplazar la amplia agenda de derechos laborales, poniendo en su lugar un estrecho elenco de cuatro pautas centrales. Esto contradice la postura tradicional de la oıт, que no daba más o menos peso a cada derecho. A su vez, abre el espacio a interpretaciones diversas y divergentes sobre el contenido de esas mismas pautas, sin atender necesariamente a los criterios de la отт. Además, la Declaración parece dar primacía a los derechos procesales en materia laboral, asociados a las libertades civiles y políticas, en lugar de fortalecer los derechos económicos y sociales. Es un enfoque, denuncian Alston y Heenan, coherente con el neoliberalismo, que fomenta la promoción y la asistencia técnica en lugar del control y la aplicación concreta de las pautas mismas.

No es novedoso, en realidad, que se adopten a lo largo del informe nociones diversas y cada vez más estrechas de los derechos humanos. Killinger (2003, p. 126) señala, como observación general, que el Banco suele tener un abordaje incoherente en este tema: no utiliza los aportes de los organismos internacionales en la materia, ni da cuenta del alcance completo de los derechos involucrados.

En cambio, el derecho de propiedad, por ejemplo, aparece más de una vez, en lugares destacados y sin restricciones ni matices. Se aconseja garantizar "derechos de propiedad claros", incluyendo los de propiedad intelectual, ya que "se halla bien establecido el vínculo entre el desarrollo y el respeto por la propiedad" (Banco Mundial, 2012, pp. 292, 297). ${ }^{7}$ Hay un tratamiento diferenciado: el estado de derecho implica "asegura[r] la puesta en vigor de los contratos"; en tanto, respecto de las cuatro pautas de la oІт abarca solamente su "realización progresiva" (pp. 22, 292), por lo que todavía pueden tolerarse violaciones en una primera etapa (de duración incierta).

En síntesis, solo un conjunto muy restringido de derechos humanos (las cuatro pautas fundamentales de la oІт) aparecen como límite de las políticas públicas en materia de empleo. Si bien en tramos anteriores del informe ha habido alguna mención del derecho al trabajo tal como aparece en la DUDH, no se lo analiza ni se explica según los aportes del Comité, no se evalúan opciones para proveerlo o garantizarlo ni se discuten argumentos académicos sobre este derecho como los que revisamos más arriba. Tampoco se hace referencia al "pleno empleo" como un objetivo fijado en el PDESC para los Estados parte.

No hay análisis del resto del articulado de la DUDH, ni del PDESC, ni de las elaboraciones del Comité DESc. La nutrición, la salud o la educación no son descriptas como derechos humanos, sino como "objetivos de desarrollo". El informe destaca que son importantes como "acumulación de capital humano", ya que "equipan a las

7 Algo similar ocurre en la edición 2005 del World Development Report, que sugiere fortalecer la seguridad de los derechos de propiedad. Esto se logra verificando los derechos sobre la tierra y otras propiedades, facilitando la exigibilidad de los contratos, reduciendo el crimen y poniendo fin a la expropiación no compensada; véase Banco Mundial, 2004, pp. 9, 79-80. 
personas para el empleo productivo". No se trata de derechos que generan obligaciones al Estado, sino de objetivos que "necesitan atención" de los gobiernos (Banco Mundial, 2012, pp. 24$25,296)$. En tanto, como se menciona más arriba, las reglas sobre propiedad aparecen como parte del Estado de derecho.

En suma, la salud, la nutrición, la educación, la propiedad y los derechos laborales reciben un trato diferenciado. Ello puede apreciarse en el siguiente pasaje del informe: "Los resultados positivos en las áreas de nutrición, salud y educación no sólo mejoran la calidad de vida de las personas, sino que también les dan las herramientas necesarias para el trabajo productivo. Las instituciones del estado de derecho incluyen la protección de los derechos de propiedad y la progresiva efectividad del ejercicio de los derechos en el trabajo, a fin de evitar una situación en que el crecimiento coexista con formas de empleo inaceptables" (Banco Mundial, 2012, p. 22). ${ }^{8}$ Analicemos el texto. Por una parte, la salud, la nutrición y la educación se presentan como aportes útiles o beneficiosos tanto en un sentido vital como productivo. No son, en cambio, descriptos como derechos. Ese carácter se reserva, como se ve en las frases inmediatas, para la propiedad y los derechos en el trabajo. Pero ambos elementos no tienen el mismo peso. La propiedad debe protegerse en el presente, mientras que el ejercicio de los derechos en el trabajo se va dando "progresiva[mente]". En otras palabras: la propiedad se tutela hoy,

8 Este pasaje se toma de la versión oficial en español publicada por el Banco, que abarca solo el primer capítulo del World Development Report. mientras que los derechos laborales no reciben genuina protección, sino solo la expectativa de que se consoliden en el tiempo. Se delinean tres segmentos: en el primero, hay hechos positivos (alimentarse, curarse, educarse); en el segundo, hay derechos que van avanzando; en el tercero, se ubica el derecho de propiedad, cuya protección se debe brindar sin demora ni postergación. Cabe preguntarse: ¿refleja este planteamiento una concepción basada en los instrumentos internacionales de derechos humanos? La respuesta es negativa. El PDESC consagra como derechos humanos la salud (art. 12), la alimentación (art. 11) y la educación (art. 13), como así también los derechos laborales (arts. 6 y 7 ); el mismo carácter tienen en la DUDH (arts. 23 a 26). La propiedad aparece como derecho humano, aunque solo en la DUDH (art. 17), no en el PDESc ni en el Pacto Internacional de Derechos Civiles y Políticos. De modo que el Banco nos muestra en este pasaje citado un esquema alejado de las normas del derecho internacional de los derechos humanos: un grupo de derechos (salud, educación, nutrición) son despojados de ese carácter y degradados a políticas deseables, mientras que la propiedad adquiere una jerarquía y una protección inmediata que se niega a los otros derechos mencionados.

La informalidad laboral no es analizada como violación de derechos humanos laborales, tal como la describe el Comité en el parágrafo 10 de su OG 18 (2005). Es que el trabajo informal no garantiza los derechos contenidos en el art. 23 de la DUDH, y probablemente implica la exclusión de la seguridad social consagrada en 
el art. 22. El análisis del Banco, en cambio, es centralmente económico, solo relacionando informalidad con baja productividad (Banco Mundial, 2012, pp. 49, 64); ${ }^{9}$ eso deja poco o ningún espacio para una revisión a partir de los derechos. El concepto de seguridad social aparece restringido: la posibilidad de obtener beneficios sociales y el seguro de desempleo debe estar condicionada, según el Banco, a mostrar "una actitud abierta" en la búsqueda de empleo ( $p$. 270). De este modo, el acceso a un derecho humano (aunque el informe no lo describa como tal) queda sujeto a un cierto estado psicológico. Resulta difícil congeniar estas condicionalidades con un enfoque de derechos humanos, donde la universalidad es la regla.

Incluso la noción de progresividad, ${ }^{10}$ que el informe asocia a los derechos laborales, no es tomada seriamente. Como se sabe, este principio acarrea la obligación de no dictar medidas regresivas, esto es, las que recortan o disminuyen el

9 Transcribimos el pasaje pertinente [la traducción es nuestra]: “El trabajo en los países en desarrollo se caracteriza por una alta prevalencia de la informalidad, ya se la defina a partir del registro de empresas, de la cobertura de la seguridad social o de la existencia de un contrato escrito de empleo. (...) Más allá de la definición específica adoptada, el empleo informal se asocia generalmente con baja productividad. Sin embargo, esto no significa necesariamente que el registro de las empresas, la cobertura de la seguridad social o un contrato escrito resultarían en una mayor eficiencia. La informalidad puede ser tanto un síntoma de baja productividad como una causa de la misma" (Banco Mundial, 2012, p. 49). No se analiza el problema de la violación de derechos del trabajador que conlleva la informalidad.

10 El principio de progresividad es una pauta reconocida en el campo de los derechos económicos, sociales y culturales. Proviene del art. 2 del PDESC, por el cual los Estados parte se comprometen a "adoptar medidas (...) hasta el máximo de los recursos de que dispongan, para lograr progresivamente, por los medios apropiados, inclusive en particular la adopción de medidas legislativas, la plena efectividad de los derechos" reconocidos en el Pacto. En la OG 3 (1990), el Comité DEsc explica que la "realización progresiva" significa que los Estados deben moverse "tan rápidamente como sea posible" hacia el pleno disfrute de cada derecho consagrado en el PDESC. Véase Kalantry et al., 2010, pp. 267-268 y, en general, Courtis, 2006. nivel alcanzado en el disfrute de un derecho. Sin embargo, el informe del Banco incluye entre las alternativas posibles ciertas políticas en tal sentido. La reforma de pensiones en Polonia es presentada como un ejemplo exitoso en materia de sustentabilidad. En aquel país europeo, explica el Banco, "los beneficios jubilatorios se ajustan hacia abajo a medida que la expectativa de vida aumenta", llevándolos a ser "significativamente más bajos que el promedio de la Unión Europea". Este ajuste hacia abajo es una regresión explícita. De acuerdo con el informe, en 2012 la edad de jubilación se elevó en dos años para los hombres y siete para las mujeres (Banco Mundial, 2012, pp. 31, 302), en un nuevo retroceso: las personas deben trabajar más años que los exigidos bajo la regulación anterior. En la práctica, esto reduce el período de descanso de la fuerza laboral, al prolongar la etapa activa.

La protección contra el desempleo es un derecho humano consagrado en el art. 23 de la DUDH. Sin embargo, el informe del Banco no toma esta base: solo subraya que "el impacto en la eficiencia" de la legislación en esta materia es relativamente modesto. ${ }^{11}$ Por lo tanto, según el

11 Este aparte, tomado de la edición oficial en español, muestra el tenor del análisis sobre la protección contra el desempleo: "En la mayoría de los países que se han estudiado, las normas sobre seguridad en el empleo y salarios mínimos tienen un efecto escaso en el empleo agregado. Esas normas ofrecen beneficios a quienes tienen cobertura, mientras que los efectos negativos tienden a concentrarse en los jóvenes, las mujeres y los trabajadores menos calificados. [...] La reglamentación afecta más claramente los flujos de empleo, al crear un efecto de 'rigidez' en el mercado de trabajo y aminorar el ritmo de la rotación del empleo. Si bien esto representa un obstáculo para la eficiencia económica, los escasos estudios empíricos de los efectos sobre la productividad son poco concluyentes" (Banco Mundial, 2012, p. 26). Se destaca la ausencia de referencia alguna a los derechos que protegen al trabajador contra el desempleo y, eventualmente, en su condición de desempleado. El análisis se mantiene en el plano de los hechos, señalando ventajas y desventajas en relación con la eficiencia económica o la productividad. Es muy diferente a la línea seguida en los pasajes referidos 
Banco, cada país puede elegir qué mecanismos de protección adoptar, "según sus preferencias normativas en materia de redistribución" (Banco Mundial, 2012, pp. 260-262). Una vez más el informe presenta una cuestión de derechos humanos como un simple problema de opciones políticas. Las obligaciones internacionales basadas en los tratados de derechos humanos se reformulan erróneamente como un grupo de opciones, entre otras, todas abiertas a los Estados. Pero en realidad el Banco va más allá. No solo no reconoce al seguro de desempleo el carácter de derecho, sino que advierte sobre sus supuestos efectos negativos: "El seguro de desempleo puede ayudar a los trabajadores a asegurarse contra los riesgos que supone la pérdida del empleo, pero también puede hacer disminuir los esfuerzos por encontrar trabajo. Cuando el seguro de desempleo, las pensiones, los servicios de salud y otras prestaciones se financian a través del salario, el nivel elevado de las contribuciones puede actuar como un desincentivo para la contratación" (Banco Mundial, 2012, p. 27). Un derecho (en este caso, la protección contra el desempleo) se describe simplemente como una opción política más, y no como una obligación de los Estados, libre y públicamente asumida al ratificar los tratados internacionales de derechos humanos. El análisis económico del Banco y su asistencia técnica a los Estados deberían partir de la existencia de esa obligación para ofrecer ideas sobre mecanismos destinados a lograr su cumplimiento.

a los derechos de propiedad (p. 25), donde se combina la descripción de procesos económicos con la exigencia normativa de la protección judicial de esos derechos.
El salario mínimo tampoco es considerado como un derecho, ni como una parte del derecho a trabajar, ni como un límite genuino al Estado y los empleadores en sus prácticas contractuales. Para calcularlo, el Banco no toma en cuenta las necesidades de un nivel de vida adecuado, según se deriva de los arts. 7 y 11 del PDESc. En cambio, centra su análisis en el impacto que tiene la fijación del salario mínimo en la eficiencia de la economía (Banco Mundial, 2012, p. 262). Se lo presenta como otro instrumento económico disponible para múltiples propósitos, no solo (ni necesariamente) para cubrir las necesidades básicas de las personas que trabajan. Por ejemplo, puede usarse en combinación con el monto de los estipendios pagados en programas de trabajo público temporario que, usualmente, son parte de medidas de protección social. Como explica el Banco, "el manejo cuidadoso del nivel salarial puede ser una herramienta para guiar la autoselección de los beneficiarios potenciales" (p. 270). Si el programa de empleo público paga un estipendio por debajo de un salario mínimo oficial atrasado, entonces solo las personas en estado de mayor necesidad se registrarán en él. Se asegura así la focalización eficiente a través de la manipulación del salario mínimo. Los niveles salariales, de acuerdo con el informe, deben en general definirse en "condiciones competitivas" (p. 263), lo que convierte al salario en un precio más dentro del mercado, contradiciendo las premisas de los tratados de derechos humanos. ${ }^{12}$

12 Veamos en mayor detalle el tramo pertinente del informe: "La representación y negociación colectivas pueden también abordar los problemas derivados del poder desigual en el mercado, por el que las empresas pueden imponer a los trabajadores individuales salarios más bajos o condiciones de trabajo inferiores a los que se darían en condiciones competitivas" (Banco Mundial, 2012, p. 263). Bajo esta visión, el en- 
Estos planteos aparecen ya en la edición 2005 del World Development Report. Al describir medidas conducentes a mejorar el clima de inversión, el Banco advierte que fijar un piso salarial demasiado alto puede reducir los trabajos disponibles para los trabajadores jóvenes o menos preparados, cuyo "potencial productivo está por debajo de ese mínimo". De esta forma, la conducta de los tomadores de empleo se adopta como criterio para establecer el salario mínimo. Esto contradice las pautas fijadas en el art. 7 del PDESC, que establece una remuneración "que proporcione como mínimo (...) Condiciones de existencia dignas para ellos y para sus familias conforme a las disposiciones del presente Pacto". No se define el monto de ese salario a partir de las reacciones de los empleadores, sino de los requisitos para una vida digna. El Banco propone, incluso, mínimos diferenciados para ciertos grupos; esto nuevamente altera el carácter de un derecho humano, ya que se introducen distinciones entre las personas sin aducir mejores razones que la conveniencia de los empleadores. A modo de ejemplo, señala que en México la erosión del salario mínimo ayuda al crecimiento del empleo femenino. ${ }^{13}$ La reco-

cuentro entre oferta y demanda terminará por definir el monto del salario, y no las necesidades del trabajador. El único remedio ofrecido por el Banco consiste en mejorar las condiciones de negociación, pero siempre reconociendo al mercado como el ámbito natural donde se determina el contenido del salario (que no es tratado, entonces, como un derecho).

13 Puede resultar de interés el pasaje pertinente de la edición 2005 del World Development Report, titulado A better investment climate for everyone. El Banco sostiene allí [la traducción es nuestra]: "Los jóvenes y otros trabajadores que carecen de capacidades o de experiencia laboral pueden tener muy pocas oportunidades de ser contratados por un salario mínimo si este se halla fijado en un nivel muy superior al del potencial productivo de ellos. En las zonas atrasadas de un país, el salario mínimo nacional puede estar más cerca del salario local promedio, afectando severamente la demanda de trabajo por parte de las peque- mendación para mejorar el clima de inversión es clara: o bien se deja caer el valor del salario mínimo hasta que no sea un obstáculo para contratar a muy bajo precio, o bien se fija un mínimo más bajo que el formal para sectores determinados (por ejemplo, las mujeres). Esto implica, por supuesto, concepciones diferenciadas de dignidad, si seguimos el texto del art. 7 del PDESC; y que precisamente el género sea la línea que marca el límite de la dignidad distinta plantea muchos más interrogantes que quedan sin respuesta satisfactoria.

La protección a las personas con discapacidad también se somete a una evaluación que deja de lado su consagración en el art. 25 de la DUDH y (de modo implícito) en el art. 9 del PDESc. Según el Banco, los beneficios por discapacidad "pueden proveer una ayuda importante en materia de ingresos, pero los costos han aumentado"; alerta que estos beneficios "pueden desincentivar el trabajo entre la población general" (Banco Mundial, 2012, p. 273) y expresa su preocupación en torno a la asistencia destinada a quienes no pueden trabajar, ya que ese apoyo podría impulsar a otros a no buscar empleo. También aquí el análisis basado en la relación costo-beneficio omite la consideración de estas prestaciones como un derecho humano consagrado en la Declaración de 1948.

\footnotetext{
ñas y medianas empresas que contratan principalmente a trabajadores de baja calificación. [...] Dados estos efectos, un creciente número de países están reevaluando los salarios mínimos, a fin de expandir las oportunidades para los trabajadores de baja calificación y alentar la formalización. Lo han hecho reduciendo la indexación del salario mínimo y también estableciendo submínimos más bajos para ciertos grupos (trabajadores jóvenes) o para mercados laborales subnacionales. Por ejemplo, se reconoce que la erosión del salario mínimo en México durante la década de 1990 impulsó el empleo femenino." (Banco Mundial, 2004, p. 144).
} 
Los derechos de los trabajadores migrantes igualmente son considerados de modo superficial. Luego de describir algunos de los problemas asociados con la migración, el informe expone las diversas posturas acerca de lo que debe hacerse: algunos, dice, favorecen la libre circulación de las personas, otros exigen barreras y controles, mientras que un tercer grupo subraya "el imperativo moral de proteger los derechos humanos de los migrantes, sin importar su situación legal”. Enseguida, indica que "ninguna de estas visiones es suficiente", ya que no logran "dar cuenta de los complejos compromisos que la migración exige en el diseño de políticas" (Banco Mundial, 2012, pp. 34, 310). Pueden señalarse dos elementos preocupantes en este razonamiento. Primero, se presenta la protección de derechos humanos como un imperativo moral, cuando en realidad se trata de obligaciones internacionales derivadas de instrumentos jurídicos vinculantes, que han sido ratificados por una amplia mayoría de Estados. Segundo, el informe pone a los derechos de los trabajadores migrantes en una mesa de negociación donde se labran compromisos e intercambios. ${ }^{14}$

14 Como ejemplos de estos compromisos, el informe sostiene [la traducción es nuestra]: "Cuanto más se gaste en proteger el bienestar de los inmigrantes, como lo reclaman sus países de origen y ciudadanos interesados, tanto más caro se volverá el empleo de esa mano de obra, y menor será el número de contratados. Cuanto más se haga para asimilar e integrar a los inmigrantes, tal como lo proponen ciertos grupos en los países receptores, menos probable será que regresen a sus países. Las políticas más activas para atraer inmigrantes con 'talentos' agravarán la preocupación de los países emisores respecto a la 'fuga de cerebros'. [...] Fijar como condición para [que un país emisor pueda] recibir ayuda financiera internacional la prohibición de emigrar parece inaceptable y afectaría derechos fundamentales de los trabajadores al restringir su libertad de movimiento" (Banco Mundial, 2012, p. 310). Aquí puede verse el esquema de los compromisos: respetar un derecho (de los migrantes) podría afectar un resultado económico, o un objetivo político (de los Estados). El Banco contrapone elementos de ámbitos distintos: obligaciones versus finalidades. De esa forma, invocar un objetivo buscado podría justificar la violación de una obligación
Al analizar cualquier política laboral, el Banco adopta un enfoque pragmático, de análisis caso por caso, en el que los derechos no son parte de los criterios definitorios. Las regulaciones en materia de trabajo deben "abordar, al menos en parte, las imperfecciones del mercado laboral sin reducir la eficiencia" (Banco Mundial, 2012, p. 27). Una genuina regulación basada en derechos, en cambio, no los reformularía a la luz de la eficiencia, ya que esta no es un derecho en sí misma. Los derechos de propiedad deben coexistir con los de los trabajadores; el derecho a trabajar no debe afectar la libertad de contratar. Sin embargo, la eficiencia, como tal, no es un derecho humano, y los demás derechos humanos no deben equilibrarse o armonizarse con ella. Al contrario, la eficiencia debe alcanzarse sin afectar los derechos humanos. Del mismo modo que la lucha contra la delincuencia debe llevarse a cabo sin violar garantías o derechos de la parte acusada. El Banco, en cambio, parece sostener una idea diferente: los derechos deben respetarse en tanto no afecten la eficiencia.

El informe somete a los derechos a un análisis de costo-beneficio, aunque se destaca que “los cálculos son diferentes cuando el objetivo que guía es el impacto general en el desarroIlo" (Banco Mundial, 2012, p. 29). La visión es más amplia, pero la base del razonamiento es la misma: la relación entre costo y beneficio.

\footnotetext{
estatal. Esta clase de razonamiento resulta ajena a la idea de un Estado respetuoso de los derechos humanos, donde ninguna finalidad política autoriza la violación de esos derechos. Queda claro, además, que el Banco es consciente de que los derechos imponen límites: por eso descarta la propuesta de intercambiar ayuda económica por restricciones migratorias. Sin embargo, el único derecho reconocido como tal es la libertad de movimiento.
} 
Según una publicación anterior del Banco, este "generalmente apoya medidas que buscan mejorar o proteger el capital humano, tales como intervenciones en el mercado de trabajo, seguros obligatorios de desempleo o vejez y apoyos monetarios focalizados", porque en su concepto tales medidas "contribuyen a la solidaridad de un país, y a la cohesión y estabilidad sociales". No se basa en el derecho a la seguridad social, por ejemplo. Los únicos límites que pueden aceptarse son los derivados de consideraciones de eficiencia. Esta situación refleja el predominio de una concepción dominante sobre los derechos humanos dentro del Banco: la de quienes se han formado en ciertas corrientes de la economía (Sarfaty, 2009, pp. 677-678). Esta postura da a los derechos humanos un carácter simplemente instrumental: su respeto se justifica solo en cuanto pueda contribuir al desarrollo económico. La implementación de estos derechos debe ser pragmática. ${ }^{15}$ Puede haber, además, compensaciones o compromisos entre los objetivos económicos y los derechos humanos debido a la escasez de recursos.

\section{A. El caso del trabajo infantil}

Incluso algunos elementos de la Declaración de 1998 de la оाт aparecen en formas debilitadas. Mientras la Declaración exige la abolición efectiva del trabajo infantil, el informe del Banco solo rechaza las peores formas. El texto presenta un recuadro con el título No toda tarea infan-

15 Por ejemplo, el Banco explica que "la India ha aprendido a convivir con complicados obstáculos regulatorios" sobre el mercado laboral a través de "un incumplimiento generalizado"; véase Banco Mundial, 2012, p. 313. til es trabajo infantil -en el original en inglés: Not all child work is child labor- (Banco Mundial, 2012, p. 66). Ese apartado argumenta que no debe tomarse estrictamente la definición de trabajo infantil adoptada por la olт o por la Convención de los Derechos del Niño (CDN). El Banco sostiene que "las pautas internacionales dan a los países algún margen para fijar los límites de la participación de niños en actividades productivas (en cuanto a la edad o a la definición de trabajo dañoso). También permiten trabajo limitado en tareas domésticas o en actividades productivas livianas que no se consideren dañosas". Además, el Banco considera que los niños trabajan "por diversas y complejas razones" y que si bien el trabajo infantil puede afectar la escolarización, la salud y la fertilidad de estos, "es difícil establecer el vínculo" causal en cuestión. "La participación de los niños mayores de 12 años en las labores agrícolas familiares y en pequeñas empresas hogareñas puede en algunos casos contribuir a la adquisición de habilidades".

De modo que aquí el Banco va más allá de la propia Declaración de la ort. En efecto, el artículo 2 de ese documento establece la "abolición efectiva de todas las formas de trabajo infantil". En tanto, el Banco reconoce que esa es la postura de la oІт, pero afirma que ese concepto no abarca todas las tareas laborales que haga un niño, y por eso propone considerar inaceptables solamente la prostitución infantil y las formas dañosas del trabajo infantil (Banco Mundial, 2012, p. 155), lo cual significa que algunas otras formas son aceptables. El PDESc (art. 10.3) establece la necesidad de fijar límites mínimos 
de edad para poder trabajar. La OG 18 (2005) establece ese umbral en los 16 años (párrs. 15 y 24), bastante más que los 12 años aconsejados por el Banco.

\section{CONCLUSIONES: LAS CONSECUENCIAS PARA ARGENTINA}

Esta concepción minimalista e instrumental de los derechos humanos en el ámbito laboral puede afectar, en principio, el proceso de discusión de políticas con los países tomadores de préstamos. Favorece una lectura estrecha de los derechos, y así puede fomentar medidas regresivas. En tal caso, los Estados se verán en una contradicción con sus compromisos emanados de tratados de derechos humanos. Por ejemplo, un préstamo para llevar a cabo una reforma del sistema jubilatorio puede incluir la elevación de la edad de retiro, o la reducción de los beneficios, como ocurrió en el citado caso de Polonia. Si el Estado tomador del préstamo es parte del PDESC y de su Protocolo Opcional ${ }^{16}$, las personas afectadas podrán presentar quejas o reclamos individuales (art. 2) ante el Comité correspondiente de Naciones Unidas, invocando el principio de no regresividad.

El ciclo de un proyecto en el Banco atraviesa distintas fases, en un prolongado diálogo de políticas sostenido con el gobierno interesado (Ghazi,

16 El Protocolo Opcional del PDESC entró en vigor el 5 de mayo de 2013. Al 31 de enero de 2014, los Estados parte del Protocolo son: Argentina, Bolivia, Bosnia y Herzegovina, Ecuador, El Salvador, Eslovaquia, España, Finlandia, Mongolia, Montenegro, Portugal y Uruguay. Ver http://treaties.un.org/Pages/ViewDetails.aspx?mtdsg_no=IV-3a\&chapter=4\&lang=en
2005, pp. 250-251; Banco Mundial, 2007, pp. 78-80). Todas las etapas quedan expresadas en diversos documentos: marco de políticas, informe de estrategia del país, etcétera, que delinean un programa macroeconómico y sus elementos sectoriales. Inicialmente, el Banco identifica proyectos que puedan contribuir al desarrollo del país cliente. Luego, este último prepara un informe detallado sobre la factibilidad del proyecto, muchas veces con asistencia del Banco. Más adelante, el Banco analiza la fundamentación técnica, las capacidades institucionales del país tomador del préstamo, la relevancia económica para el desarrollo y la disponibilidad de fondos adicionales. Luego de esto, el Banco, a través de una serie de conversaciones con el país cliente, da forma al proyecto definitivo. Este documento se presenta ante el Comité Ejecutivo para su aprobación. Si resulta aceptado, se firma el acuerdo para el préstamo y el país receptor inicia la implementación. Cuando concluya, el Grupo Independiente de Evaluación (perteneciente al Banco) examinará los resultados, pero su informe no es público.

Este esquema dialógico tiene un importante límite: el documento final debe resultar aceptable para el Comité, instancia donde los países industrializados tienen un poder decisivo. Parece difícil apartarse de los enfoques economicistas que predominan en la institución, y más aún, de las lecturas restrictivas de los derechos de los trabajadores, tales como las que se ofrecen en la edición 2013 del World Development Report.

Argentina ha dado la máxima jerarquía a los tratados de derechos humanos (art. 75 inc. 22 de 
la Constitución nacional), incluyendo a la cDN, el PDESC y la DUDH. Sus cláusulas, como el resto de los artículos de la Constitución, tienen carácter supremo en el orden jurídico interno (art. 31 de la norma; es un texto similar al de la supremacy clause incluida en la Constitución estadounidense, art. VI). Ni las leyes ni los contratos laborales pueden contradecir los derechos constitucionales. Si lo hacen, puede impugnarse su constitucionalidad, incluso por vía judicial ante acciones u omisiones que los afecten, a través, por ejemplo, de la acción de amparo prevista en el art. 43 de la Constitución. También organizaciones no gubernamentales o el Defensor del Pueblo pueden presentar amparos a nombre de grupos o colectivos. En esos casos, los efectos de la sentencia abarcan a todo el conjunto afectado.

En virtud de su orden constitucional, Argentina no puede suscribir acuerdos internacionales que violen sus obligaciones en materia de derechos humanos, ni implementar políticas que contradigan las pautas constitucionales. Los acuerdos con el Banco son simples tratados internacionales, que en virtud del art. 27 de la cN deben estar "en conformidad con los principios de derecho público establecidos en esta Constitución”. Esto significa subordinación a los principios constitucionales (Quiroga Lavié, 2000, pp. 152-153), incluyendo los derechos consagrados en los artículos del texto y en los instrumentos de igual jerarquía.

Un enfoque como el adoptado por el Banco en la edición 2013 del informe implica, entonces, un riesgo para nuestro país. La negociación de créditos puede acarrear la aceptación de polí- ticas o propuestas que recorten o debiliten el peso de derechos humanos, y que podrán ser cuestionadas judicialmente. A modo de ejemplo podrían citarse: elevación de la edad jubilatoria, flexibilización de la prohibición del trabajo infantil, revisión a la baja del seguro de desempleo para incentivar la búsqueda de trabajo, debilitamiento de la protección a los trabajadores migrantes para favorecer su retorno, salarios mínimos diferenciados por grupo etario o zona geográfica, o reducción de la paga en planes de empleo. Estas medidas se exponen en el informe del Banco. Como ya hemos visto, ellas resultarían contradictorias con el principio de progresividad (PDESC, 2) y con derechos constitucionales específicos, tales como el derecho del niño a no ser explotado económicamente (CDN, 32; PDESC, 10.3), el derecho a la igualdad de trato de nacionales y extranjeros (cN, 20), al salario mínimo, vital y móvil, y a recibir igual remuneración por igual tarea (cN, 14 bis; PDESc, 7.a). Todo ello, además, con la consecuencia de engrosar la deuda externa del país a partir de los créditos concedidos por el Banco a fin de implementar las reformas adoptadas.

\section{Bibliografía}

"Álvarez". (2010). Álvarez, Maximiliano y otros c/ Cencosud SA s/ acción de amparo. Fallos, 333:2306. 7 de diciembre de 2010.

“Aranda". (1992). Aranda, Oscar Eugenio y Cuello, Ángel Leonardo c/ Capitanía de Puertos del Litoral Fluvial. Fallos, 315:2804. 24 de noviembre de 1992. 
"Asociación Benghalensis". (2000). Asociación Benghalensis y otros c/ Ministerio de Salud y Acción Social - Estado Nacional s/ Amparo ley 16.986. Fallos, 323:1339. 1 de junio de 2000.

“Q. C.”. (2012). Q. C., S. Y. c/ Gobierno de la Ciudad de Buenos Aires s/ amparo. Fallos, 335:452. 24 de abril de 2012.

“Rodríguez". (2006). Rodríguez, Karina Verónica c/ Estado Nacional y otros s/ acción de amparo. Fallos, 329:553. 7 de marzo de 2006.

Abouharb, M. R. y Cingranelli, D. (2007). Human rights and structural adjustment. Cambridge (Gran Bretaña): Cambridge University Press.

Abramovich, V. y Courtis, C. (2002). Los derechos sociales como derechos exigibles. Madrid: Trotta.

Alston, P. y Heenan, J. (2004). Shrinking the international labor code: an unintended consequence of the 1998 ILo Declaration on Fundamental Rights and Principles at Work? New York University Journal on International Law and Politics, 36(2-3), 221-261.

Banco Mundial. (1993). Contribution from the World Bank. The World Bank and the promotion of human rights. UN Document A/ CONF.157/PC/61/Add.19.

Banco Mundial. (2004). World Development Report 2005. A better investment climate for everyone. Washington (D.C.): World Bank.
Banco Mundial. (2007). A guide to the World Bank. (2 ${ }^{a}$ ed.). Washington (D. C.): World Bank.

Banco Mundial. (2012). World Development Report 2013. Jobs. Washington (D. C.): World Bank.

Bidart Campos, G. J. (1991). Teoría general de Ios derechos humanos. Buenos Aires: Astrea.

Committee on Economic Security. (1935). Report of the Committee on Economic Security - 15 January 1935.

Corbalán, M. (2002). El Banco Mundial. Intervención y disciplinamiento. El caso argentino: enseñanzas para América Latina. Buenos Aires: Biblos.

Courtis, C. (2006). La prohibición de regresividad en materia de derechos sociales: apuntes introductorios. En Christian Courtis (comp.). Ni un paso atrás. La prohibición de regresividad en materia de derechos sociales (pp. 3-52). Buenos Aires: Editores del Puerto.

Darrow, M. (2003). Between light and shadow. The World Bank, the International Monetary Fund and International Human Rights Law. Portland: Hart Publishing.

Fine, B. (2002). The World Bank's speculation on social capital. En J. R. Pincus y J. A. Winters (eds.). Reinventing the World Bank (pp. 203-221). Ithaca y Londres: Cornell University Press. 
Ghazi, B. (2005). The IMF, the World Bank and the question of human rights. Ardsley (Nueva York): Transnational Publishers.

Harvey, P. (2007). Benchmarking the right to work. En M. Alanson y S. Hartel (eds.), Economic Rights: Conceptual, Measurement and Policy Issues (pp. 115-141). Cambridge (Gran Bretaña): Cambridge University Press.

Harvey, P. (Spring, 2002). Human rights and economic policy discourse: taking economic and social rights seriously. Columbia Human Rights Law Review, 33, 363-471. Recuperado de http://www.ilo.org/employment/about/ executive-director-office/statements-speeches/ WCMS_192350/lang--en/index.htm; http://www. ssa.gov/history/reports/ces5.html

Kalantry, S., Getgen, J. y Arrigg Koh, S. (2010). Enhancing enforcement of economic, social and cultural rights using indicators: A focus on the right to education in the ICESCR. Human Rights Quarterly, 32, 253-310.

Kanbur, R. y Vines, D. (2000). The World Bank and poverty reduction: past, present and future. En C. Gilbert y D. Vines (eds.), The World Bank. Structure and policies (pp. 87-107). Cambridge (Gran Bretaña); Cambridge University Press.

Killinger, S. (2003). The World Bank's non-political mandate. Colonia-Berlín-Munich: Carl Heymanns Verlag KG.
Klein, P. (1999). Institutions financières internationales et les droits de la personne. Revue Belge de Droit International, XXXII(1), 97-114.

Murillo, S. (2008). Colonizar el dolor. La interpelación ideológica del Banco Mundial en América Latina. El caso argentino desde Blumberg hasta Cromañón. Buenos Aires: cLAcso.

Organización Internacional del Trabajo. (2012). ILO (Office) comments on the World Bank's 'World Development Report 2013: Jobs'.

Quiroga Lavié, H. (2000). Constitución de la Nación Argentina. Comentada. ( $3^{\mathrm{a}} \mathrm{ed}$.). Buenos Aires (Argentina): Zavalía.

Ribe, H., Carvalho, S., Liebenthal, R., Nicholas, P. y Zuckerman, E. (1990). How adjustment programs can help the poor. The World Bank's experience. World Bank Discussion Papers número 71. Washington (D. C.): World Bank.

Sagüés, N. P. (2007). Manual de derecho constitucional. Buenos Aires: Astrea.

Sarfaty, G. (2009). Why culture matters in international institutions: the marginality of human rights at the World Bank. American Journal of International Law, 103, 647-683.

Sepúlveda, M. (2006). La interpretación del Comité de Derechos Económicos, Sociales y Culturales de la expresión 'progresivamente'. En C. Courtis (compilador). Ni un paso atrás. La prohibición de regresividad en materia de 
derechos sociales (pp. 117-150). Buenos Aires: Editores del Puerto.

Sindzingre, A. (2004). The evolution of the concept of poverty in multilateral financial insti- tutions. The case of the World Bank. En M. Bøås y D. McNeill (eds.), Global institutions and development. Framing the world? (pp. 164-177). Londres y Nueva York: Routledge. 